\title{
A New Analysis of Verbal Irony
}

\author{
Yasir Alotaibi (Corresponding author) \\ College of Education, Prince Sattam bin Abdulaziz University, Saudi Arabia \\ E-mail: yasirho@hotmail.co.uk
}

Received: 17-02-2017

Accepted: 04-05-2017

Advance Access Published: July 2017

Published: 01-09-2017

doi:10.7575/aiac.ijalel.v.6n.5p.154

URL: http://dx.doi.org/10.7575/aiac.ijalel.v.6n.5p.154

\begin{abstract}
This article contributes a new analysis of verbal irony to the literature. It presents the main analyses of verbal irony and the main criticisms of these analyses - found in both older and modern literatures as part of its attempt to build a new account for verbal irony. Thus, this paper discusses traditional, echoic and pretense accounts of irony and the limitations of these analyses. In traditional account, verbal irony is analyzed as a type of a trope or a figurative, in which the speaker communicates the opposite of the literal meaning (see Utsumi (2000)). In echoic analysis, verbal irony is assumed to be an echoic interpretation of an attributed utterance or thought (see Wilson and Sperber (1992)). As for pretense account of verbal irony, it views the ironist as pretending to be an injudicious speaker talking to an uninitiated hearer (see Clark and Gerrig (1984)). The three analyses of verbal irony attract some criticism in the literature (see Kreuz and Glucksberg (1989) and Utsumi (2000)). This paper argues for a new analysis, suggesting that there are multiple types of verbal irony that should be examined under more than one analytical approach based on their meanings. This paper suggests that ironic verbal expressions that communicate the opposite of their literal meaning should be analyzed as a type of metaphor with two oppositional subjects in which the ironist pretends to believe that they resemble one another.
\end{abstract}

Keywords: ironist, echoic, pretense, verbal irony

\section{Introduction}

Verbal irony is an important linguistic phenomenon that was discussed by a variety of scholars in many languages. The traditional analysis defines verbal irony as a trope that substitutes a figurative meaning for the literal meaning of an utterance. However, in ironic utterances, the figurative meaning represents the opposite of the literal meaning. For example, a typical example of verbal irony is when a speaker finds the weather to be terrible and utters the following sentence:

(1) The weather is lovely.

This phenomenon has attracted the attention of researchers from different fields. The important question to address involves how to analyze verbal irony. For many centuries, researchers have attempted to suggest an analysis for verbal irony in many languages. In classical rhetoric, verbal irony is analyzed as a trope or metaphor in which the literal meaning is the opposite of the intended meaning (see Clark and Gerrig (1984) and Wilson and Sperber (1992)). In early pragmatics, verbal irony is analyzed as implicating the opposite of the literal meaning by Grice (1975). The problem of this analysis is that it cannot account of all the types of verbal irony.

New studies also attempt to account for verbal irony through echoic and pretense accounts, most importantly. In the echoic description, verbal irony is analyzed as an echoic utterance (Sperber and Wilson, 1981) or an echoic interpretation (Wilson and Sperber, 1992). However, this analysis is also unable to account for some types of verb irony and it is difficult to assume that the ironist echoes an interpretation of another utterance or thought. In the pretense description, as proposed by Clark and Gerrig (1984), verbal irony is assumed to be a pretense in which the ironist pretends to be an unseen person who speaks to an unknown addressee, but the main problem in this analysis is that the hearer identifies neither the unseeing person nor the unknowing hearer and this analysis is also unable to account for all the types of verbal irony.

Popa-Wyatt (2014) discusses the strengths and weaknesses of pretense and echoic accounts of verbal irony and proposes a new account that integrates both accounts. Popa-Wyatt (2014) argues that pretense and echoic concepts are necessary to account for verbal irony, meaning that every example of verbal irony should involve both pretense and echo at the same time. However, the main problem in this proposal is that it makes the analysis of verbal irony more complicated and could not avoid the weaknesses in both accounts of irony, as the author claims.

Additionally, some studies related to verbal irony try to account for similar phenomenon. For example, Camp (2012) sEp pisiscusses sarcasm and argues that it should be analyzed in terms of meaning inversion, which was suggested in traditional theory of sarcasm. However, the author believes that the word 'meaning' should be construed broadly to include illocution, attitudes and propositional content. Sarcasm and verbal irony are related in spite of some differences between them, making sarcasm more pointed and negative than verbal irony. Carston and Wearing (2015) discuss the 
relation between hyperbolic language and irony, arguing that there is a huge difference between hyperbolic use of language and irony.

This paper discusses the traditional, echoic and pretense accounts of verbal irony, which are the most important accounts of verbal irony. It presents these analyses and summarizes the criticisms of these accounts found in the literature. The paper contributes a new analysis of verbal irony, arguing that ironic expressions have different meanings and should therefore be examined using more than one analytical approach. This paper suggests a new analysis for verbal irony that communicates the opposite of the literal meaning and further argues that this type of irony should be viewed as a metaphor comparing two subjects in which the speaker pretends to believe that these subjects resemble one another.

The paper is divided into six sections. The first and sixth sections are the introduction and conclusion. The second section discusses traditional accounts of irony in Arabic and western literature and sheds light on the relevant criticisms of these accounts. The third section discusses the echoic account of irony, and the fourth section discusses pretense theory. The fifth section presents a new analytical approach to verbal irony, in which all types of verbal irony that communicate the opposite of the literal meaning are analyzed as a type of simile or metaphor that compares two subjects that are opposite of one another, but the speaker pretends to believe that they resemble one another.

\section{Traditional analysis}

This section discusses the traditional account of irony in the literature. It begins with descriptions of irony found in classical Arabic rhetoric and then discusses the traditional account of irony found in western literature. This section also shows some problems with the traditional accounts of irony that are found in both the Arabic and western literary traditions.

Three types of verbal irony are discussed in classical Arabic rhetoric. The first type resembles the example typically considered in a pragmatic analysis, in which the speaker does not aim to communicate the literal meaning of his/her utterance but instead attempts to communicate the opposite of the literal meaning. A typical example of irony found in old Arabic literature (2) illustrates when the speaker thinks that Salem is not cleverı:

(2) Salem is clever.

Alzamakhshariy (nd) discusses similar examples of irony and attempts to explain the phenomenon by positing that the speaker intends the opposite of the utterance's literal meaning. He further explains that the goal of this type of irony is to express mockery and ridicule.

The second type of irony discussed in classical Arabic literature is when the speaker uses simile to convey ironic meanings. The speaker compares one thing to its opposite, claiming similarity by using connecting words such as like or as. The following example illustrates this type of irony, in which Hatem was known as a generous man in Arabic history and the speaker believes that Salem is a very stingyman

(3) Salem is like Hatem.

The example in (3) may be developed into an example of metaphor, as in example (4). In example (4), the speaker claims that Salem is Hatem in a literal sense. However, the intended meaning is that Salem, who is a stingy man, is the opposite of Hatem, who is a generous man, and the speaker uses this metaphor to express mockery and ridicule:

(4) Salem is Hatem.

The example in (4) can be developed into the third type of irony discussed in classical Arabic rhetoric. In this type of irony, the speaker uses the proper noun Hatem in referring to Salem. The aim of the speaker remains the same, that is, to express mockery and ridicule. However, the mockery in this type of irony is rhetorically more sophisticated than in the previous examples. In example (5), the speaker uses Hatem to refer to Salem:

(5) Hatem is coming.

This discussion of irony from the old Arabic literature is similar to a related discussion in the western classics. Verbal irony is considered a trope in classical western rhetoric that is assumed to express figurative meaning. In verbal irony, the relation between the literal meaning of an utterance and its figurative meaning is a comparison (see Wilson and Sperber (1992) and Wilson (2006)).

Grice develops the modern pragmatic analysis of verbal irony. In Grice (1975), the speaker uses verbal irony by deliberately violating the maxim of truthfulness, the first maxim of Quality that states 'do not say what you believe to be false' (Levinson, 1983, 101). In this case, we assume that the speaker implicates the opposite of the literal meaning of his/her utterance (also, see Grice (1978)). The important difference between classical rhetoric and Grice (1975) is that Grice analyzes verbal irony as a figurative implication instead of as figurative meaning.

The traditional account of irony, which considers irony as a type of a trope or figurative implication, has endured some criticism in the literature (see Wilson and Sperber (1992) and Utsumi (2000)). The main argument against the traditional account of irony is that it cannot account for all types of irony, such as ironic understatements, ironic quotations, and

1 There is no need to write the examples in this subsection using literal Arabic words, as this section will instead utilize simple meanings that can be presented in English sentences. 
(6) a. (Context: You saw an angry man complaining about something and you told your friend the following sentence:)

b. He is upset.

(7) a. (Context: You are in England during a cold English spring and say the following sentence:)

b. 'Oh to be in England. Now that April's there' (Wilson and Sperber, 1992,55).

(8) a. (Context: You invited me to visit London in the summer and said that London has good weather in the summer, then I found that the weather in London was cold and uttered the following:)

b. Ah, London in the summer.

\section{Echoic account}

This section considers a different modern pragmatic analysis of verbal irony. It opens with mention theory and its explanation of verbal irony, then discusses the development of echoic theory. Finally, this section discusses some problems with the analysis that hinder its assessment of verbalirony.

\subsection{The mention theory}

Sperber and Wilson (1981) argue against the traditional approach to verbal irony and believe that the analysis should instead focus on irony's allusive nature. This account of irony is based on a distinction between use and mention (see Jorgensen et al. (1984) and Clark and Gerrig (1984)). This distinction was proposed to address the difference in using a word such as Mary in the following example:

(9) a. Mary is a beautiful girl.

b. 'Mary' is a beautiful name.

In (9a), the word Mary refers to a girl, whereas in (9b) it is used to refer to a word. Thus, the word Mary in (9a) is used whereas it is mentioned in (9b). In example (9b), quotation marks are used to show that the word Mary is mentioned, although in this example the reader easily understands this without the need for quotation marks. Nonetheless, mentioned names or expressions are sometimes difficult to understand without quotation marks in written language or contextual clues in spoken language. For example, the question in (10a) may be answered by the sentence in (10b) or (10c), where both sentences contain the same words but convey different meanings:

(10) a. Sam: What did David say?

b. Louise: I will speak with you later.

c. Louise: 'I will speak with you later'.

The answer in (10c) contains quotation marks to show that the sentence is mentioned, while the sentence is used in the answer in (10b). The quotation marks in (10c) are necessary in written language because the reader would not be able to distinguish the different meanings that are expressed by both sentences with the same words. In example (10b), the "used" statement, the referent of the pronoun I is Louise, and the referent of the pronoun you is Sam. By contrast, the referent of the pronoun I in (10c) is David, and the referent of you is Louise. Louise's answer cannot be understood by $\mathrm{Sam}$ if he does not recognize whether the sentence is used or mentioned.

Louise's answer in (10c) is a direct quotation, meaning that it is mentioned in a direct manner. However, Sperber and Wilson (1981) argue that indirect quotations can also be analyzed as being "mentioned". The indirect quotation in (11) below can act as an answer for the question in(10a):

(11) Louise: He would speak with me later.

The answer in (11) can have two interpretations that are close to the responses in (10b) and (10c) above. In the first interpretation, Louise is not reporting David's speech (because he did not speak); instead, she is saying that David will speak to her later. This interpretation is similar to the answer in (10b), in which Louise's utterance is used rather than mentioned. In the second interpretation, Louise is reporting David's utterance, meaning that it is similar to the answer in (10c), in which the utterance is mentioned. In the last interpretation, Louise reproduces the meaning of David's utterance with different words.

The second interpretation of the utterance in (11) is not as a direct quotation, which means it cannot be analyzed as mentioning David's utterance. Therefore, the difference between the two interpretations of (11) cannot be explained by employing the distinction between use and mention. To solve this problem, Sperber and Wilson (1981) suggest that these types of sentences contain a distinction between the use and mention of propositions. In other words, the sentence in (11) presents a proposition that may be used to express the meaning of the first interpretation or mentioned to express the meaning of the second interpretation. 
Sperber and Wilson (1981) argue that verbal irony is a type of indirect quotation in which the ironist is mentioning a proposition. These authors divide indirect quotations into two types: reporting and echoing. If the speaker reports an utterance or thought, he/she gives information about its content. By contrast, if the speaker echoes an utterance, he/she expresses his/her attitude and reaction to this utterance. Irony is thus a variety of echoic utterance.

This analysis can account for some examples of verbal irony. For example, David asked Mary about the weather in England during the winter and she said it is very nice. Then, David went to England in the winter, found the weather there to be very cold, and uttered the statement in example (12):

(12) David: It is very nice.

The example in (12) is an illustration of verbal irony. David echoes Mary's utterance to indicate that it is ridiculous and misleading. The hearer can understand that the example in (12) is ironic if he/she realizes it is echoic and recognize the attitude included in the speaker's tone.

Not all types of verbal irony are as easy to recognize as example (12). Sometimes the speaker does not echo an utterance that is attributed to someone else. Instead the speaker may echo a thought that was not uttered or that is not attributable to any person. For example, David in example (12) may utter this sentence without hearing anything from Mary. David may echo the idea that England has good weather, which could be attributed to Mary or perhaps to other people. Therefore, the mention theory is criticized in the literature for being too narrow and unable to account for all cases of irony. Many types of irony do not require the speaker to echo another utterance; thus, Wilson and Sperber (1992) develop a theory that accounts for additional types of irony.

\subsection{Echoic interpretations}

The echoic analysis is developed by Wilson and Sperber (1992), who described an echoic utterance as an echoic interpretation of an attributed utterance or thought. Verbal irony is analyzed as a type of echoic interpretation of an attributed utterance or thought because the use-mention theory does not account for all types of echoic utterances.

There is a distinction between interpretive use and descriptive use. When an utterance is used in a descriptive manner, it represents an actual or possible state of affairs. By contrast, when an utterance is used in an interpretive manner, it represents another utterance or thought that it resembles in content (see Wilson(2006)).

An utterance resembles another if the two utterances share some properties. However, two utterances can also interpretively resemble one another if they share contextual or logical implications. One utterance is a literal interpretation of another if it uses all the same implications; otherwise, the two utterances simply have implications in common. Wilson and Sperber (1992, 65-66) explain the difference between the two types of resemblance using examples such as the following. Mary told Peter that she met an agent and said the following sentence:

(13)Mary: 'He can make me rich and famous'.

If the agent utters the sentence in example (14) to Mary, Mary's utterance will be a literal interpretation of the speech of the agent.

(14) The agent: 'I can make you rich and famous'.

However, if the agent instead says the sentence in (15), Mary's utterance and the agent's utterance only have implications in common.

(15) The agent: 'I can do for you what Michael Caine's agent did for him'.

Wilson and Sperber (1992) claim that verbal irony is not a literal implication of an attributed utterance or thought, but it is an interpretation of an attributed utterance or thought.

The hearer can understand an utterance that is interpretively used if he/she recognizes that the speaker is not thinking directly about a state of affairs but instead about another thought or utterance. Additionally, in this type of use, the speaker neither asserts the proposition of his/her utterance nor takes responsibility for its truth. Instead, he/she metarepresents an utterance or thought that has a similar content and attributed to a specific person or group of people. The main point of irony is that the speaker utters an attributed thought or utterance and then dissociates himself/herself from it by expressing an attitude such as mockery, rejection, etc.

For example, if Mark attended a difficult meeting and then uttered the following sentence:

(16) Mark: The meeting was good.

In an echoic analysis of irony of this utterance, Mark should be understood to be echoing another utterance that asserts that the meeting will be good, or Mark may be echoing hopes or expectations to show that he found them to be ridiculous or misleading. In his utterance, Mark does not assert its proposition but instead dissociates himself from another utterance or thought with similar content (see Wilson and Sperber (1992) and Wilson (2006)).

Echoic interpretation theory cannot account for all types of irony. Thus, some cases of irony might be explained by assuming that the speaker is echoing the interpretations of an attributed utterance, thought, cultural norm or expectation and dissociates himself/herself from these materials. However, this theory is also too narrow and fails to explain all types of irony. The examples of irony in Arabic, which are discussed above, cannot be explained under echoic interpretation theory in some contexts. In this analysis, the speaker of example (17b) should be assumed to echo example (17a), but this is not possible because Zayd should be stingy and no one believes that he is generous. 
(17) a. Zayd is generous.

b. Zayd is like Hatem.

In an echoic interpretation of irony, a speaker interpretively echoes another utterance or thought if the two propositions of the utterances share some logical or contextual implication. However, it is not possible to assume that the speaker in (17b) interpretively echoes the utterance in (17a) because the two utterances do not share any implications and do not share any implications with general norms or universal desires. There are more examples in the literature criticizing this account of irony, but they are too numerous to discuss in any detail in this analysis (see Clark and Gerrig (1984), Kreuz and Glucksberg (1989), Giora (1995), Kumon-Nakamura et al. (1995) and Utsumi (2000)).

Giora (1995) highlights another problem with echoic interpretation theory that makes it incomplete and unable to account for verbal irony. Thus, Giora (1995) argues that this theory does not explain how verbal irony can be distinguished from other types of interpretive echoes that are used for non-ironic purposes. For example, the following utterance in $(18 \mathrm{~b})$ from Giora $(1995,248)$ is echoic because Mira mentions the utterance of the Prime Minister and expresses her negative attitude, but this utterance is not ironic. Thus, according to the definition of irony in this theory, it would be incorrect to treat this utterance as ironic.

(18) a. 'Dina: I missed the last news broadcast. What did the Prime Minister say about the Palestinians?'

b. 'Mira (with ridiculing aversion): That we should deport them'.

\section{Pretense analysis}

This section discusses the pretense account proposed by Clark and Gerrig (1984), which is a different approach to verbal irony. It opens by explaining their analysis of irony and then discusses some problems with this approach.

Clark and Gerrig (1984) propose a different approach to verbal irony - the pretense account - that criticizes the mention theory and constructs a new theory that avoids some of the problems of the mention and the echoic theories. The main idea in pretense theory is to view the speaker as pretending to be an injudicious speaker talking to an uninitiated hearer. In other words, the speaker in this approach does not actually perform a speech act, such as asking a question or making an assertion; instead, he/she only pretends to be a person who is performing it. This account is also found in theories of mimesis or simulation (see Walton (1990), Nichols and Stich (2000), Currie and Ravenscroft (2002), Currie (2004) and Recanati (2000, 2004)).

For example, if a speaker utters the sentence in (19) in the context of the speaker believing that David is a bad friend, then the pretense in this ironic example can be explained as follows: the speaker is pretending to be an unseeing person who is speaking to an unknowing hearer and is telling them that David is a good friend. The speaker intends to show the addressee how ridiculous it would be to think that David is a good friend by pretending to be another person, who is injudicious and who is speaking to an uninitiated addressee.

(19) David is a good friend.

According to Clark and Gerrig (1984), this account of irony can explain some important aspects of verbal irony. The first is called the asymmetry of affect. An ironist typically prefers positive sentences to negative sentences. For example, an ironist is supposed to say David is a good friend when he is a bad friend, rather than Louise is a bad friend when she is a good friend. Jorgensen et al. (1984) posit that the world is typically viewed by norms of excellence and success rather than in terms of failure and deficiency. In pretense theory, the speaker pretends to be the person who follows these norms and therefore makes positive pretenses.

The second aspect of verbal irony involves victims of irony. An ironic utterance should have victims. Pretense theory sorts these victims into two types. The first is the person the speaker pretends to be, who is a victim of his/her own misjudgment. The second is the audience spoken to by the unseeing person, who is also a victim because of their uncritical acceptance. Echoic theory is unable to specify these two victims.

The third aspect that pretense theory is able to explain is ironic tone of voice. When an actor plays a role in a movie or series, he/she changes his/her voice to be appropriate for the role. An ironist is the same in that when he/she pretends to be another speaker he/she leaves his/her own voice for another that is appropriate for the unseeing speaker. The pretense account of irony is able to explain the change in a speaker's voice when he/she utters an ironic expression.

Pretense theory has attracted some criticism in the literature. Some researchers, such as Sperber (1984), Kreuz and Glucksberg (1989) and Utsumi (2000), claim that pretense is not a necessary aspect of irony. One problem with the theory is that imaginary people are assumed: the speaker pretends to be an imaginary person who speaks to an imaginary hearer. This structure is problematic because the addressee is not necessarily aware of the existence of both or either of the imaginary people. For example, an ironist in a bad city utters the following sentence:

(20) What a beautiful city.

In the pretense account, the ironist pretends to be an unseeing person speaking to an unknowing audience. The problem is that the hearer identifies neither the unseeing person nor the unknowing audience.

Another problem with this theory is suggested by Utsumi (2000), who posits that the argument of Clark and Gerrig (1984) regarding the victims of irony makes the pretense account less convincing. Clark and Gerrig (1984) suggest two types of victims: the person who the speaker pretends to be and the imaginary audience who accepts this person's 
utterance. Utsumi $(2000,1779)$ claims that the victim might be the hearer in an ironic utterance. For example, a mother asks her son to clean his room, finds that he did not do so, and then says the following:

(21) 'This room is totally clean'.

The victim in this utterance is the son, and it is not reasonable to assume that the mother is pretending to be her son or that the son is an imaginary hearer. Therefore, Utsumi (2000) states that the imaginary people in this analysis are dubious and that the analysis of irony should not involve pretense.

Pretense theory faces additional criticism because it cannot distinguish between irony and other utterances that involve some type of pretense, such as parody (see Sperber (1984)). Moreover, Kreuz and Glucksberg (1989) argue that this theory can be applied to all types of indirect speech acts.

Pretense theory is developed by Clark (1996), who argues that irony should be analyzed as a joint pretense in which the imagination, rather than a speaker or hearer, is suggested to be present in a certain situation. In this assumption, a joint pretense between the speaker and the hearer creates an imaginary situation, which leads to an ironic utterance. For example, the mother and her son in example (21) are pretending that they are in an imaginary situation in which the mother praises her son for cleaning his room.

Clearly, this development in pretense theory does not solve the problems listed above. In particular, the overlap between irony and non-irony and the problem of victims persist in the joint pretense view. Utsumi (2000) adds a new problem, arguing that the joint pretense account assumes that the addressee of an ironic utterance intended to pretend along with the ironist beforehand, yet this is clearly often not the case.

\section{Suggested analysis}

This section presents a new analysis for verbal irony by arguing that verbal ironic expressions have different meanings and that they should be subject to more than one analysis based on these meanings. This section suggests a new analysis of irony that combines the notion of metaphor and the notion of pretense to construct a new view that can account for irony that communicates the opposite of literal meaning.

This paper suggests that ironic sentences have different meanings and should not be analyzed under a single analytical approach. Therefore, ironic sentences such as the one in example (6), repeated in (22), which are called ironic understatements, should not be treated under the same analytical approach as an ironic sentence that is uttered by a speaker who aims to communicate the opposite meaning of his/her literal utterance. In ironic understatements, the speaker is assumed to say less than what he/she means, not the opposite of what he/she means. Therefore, this type of irony should not be analyzed together with other types of irony in a uniform analysis.

(22) a. (Context: you saw an angry man complaining about something and you spoke the following sentence to your friend:)

b. He is upset.

This means that the ironic example in (22) does not mean that he is not upset (the opposite of its literal meaning) and it differs from an example such as the weather is lovely if the weather is bad. The difference between the two types of irony is in the way that the speaker expresses mockery and ridicule. In an example such as the weather is lovely, the speaker expresses mockery and ridicule by claiming the opposite of reality. By contrast, in example such as he is upset, the situation is different in that the speaker's claim is not far from reality and the mockery and ridicule are expressed by claiming something that is less than what is happening in reality. Based on this huge difference between these types of irony, this paper claims that irony should have more than one analysis based on the differences between multiple types of irony.

This paper suggests that all types of verbal irony that communicate the opposite of their literal meanings should employ a separate analytical approach. It argues that an ironic expression that communicates the opposite of its literal meaning is a type of simile or metaphor that compares two subjects. These subjects are the opposite of one another, but the ironist pretends to believe that they resemble one another. The claim of resemblance between opposite subjects explains the mockery and ridicule that the ironist intends to convey with the ironic utterances.

This paper uses the term of metaphor in the same sense that is used by Lakoff and Johnson (2003), in which metaphor is defined as one domain is conceived and used in terms of another, meaning that this term entails a cross-domain mapping. In the following examples of irony, this cross-domain mapping will be explained.

The claim of this paper is clear in example (3), repeated in (23), in which the ironist claims that Salem, who is a stingy man, resembles Hatem, who is a generous man. The speaker in this example pretends to believe that they resemble one another. The hearer will recognize this pretense only if he/she previously knew that Salem is stingy and that Hatem is generous. The pretense in this analysis is assumed to be similar to that in pretense theory. However, this paper suggests that there is no need to assume that the speaker is pretending to be another person speaking to an unknowing hearer. The speaker in this analysis is pretending to believe something that should not be believed, which thereby associates mockery and ridicule with this type of utterance. In this example, the speaker uses a simple simile by connecting the two subjects with like.

(23) Salem is like Hatem. 
Additionally, it is easy to apply this assumption to examples (4) and (5), which are repeated below in (24):

(24) a. Salem is Hatem.

b. Hatem is coming.

As a general matter, both examples are similar to example (23). In (24a), the speaker claims that Salem is really Hatem. However, this paper claims that two types of pretense can be understood in this example. First, the speaker pretends to believe that Salem is a generous man. Second, the speaker pretends to believe that Salem not only resembles Hatem but also is in fact Hatem. As a result, this paper claims that all types of metaphor involve some type of pretense. Even if Salem is a generous man, example (24a) includes a type of pretense that makes this example more rhetorical. The case in example (24b) is the same, as the speaker exaggerated and used the name Hatem to refer to Salem. The use of the term metaphor with these examples is in the same way as in Lakoff and Johnson (2003). In both examples above, the proper noun Salem refers to a stingy man, which is the first domain, but the speaker changes the reference of this proper noun and makes it to refer to a generous man, which is Hatem, and this is the second domain.

However, the case illustrated in example (2), repeated in (25), is more complicated than the previous examples. This paper suggests that example (25) is analytically the same as the previous examples, and that it is also a type of metaphor. However, two questions are raised that this section will aim to answer. First, how can this example be analyzed? Second, why is this analysis necessary?

\section{(25) Salem is clever.}

To answer the first question, this paper suggests that example (25) has two subjects and that the speaker pretends to believe they resemble one another. The first subject is Salem, who should be a stupid man, and the second is an imaginary person who is clever. The ironist in this example claims that Salem resembles the imaginary person in the same way that the examples in (24) make similar claims, in which the speaker uses the name of the second person to refer to the first. This example contains two domains as well: in the first, Salem is a stupid, which is a real domain, and in the second Salem is clever. The speaker uses Salem in the second domain.

As for the second question, it is clear that the main support for this analysis comes from the previous examples in (23) and (24). Therefore, this analysis provides a plausible explanation for all types of irony that communicate the opposite of literal meaning.

In general, the main benefit of the suggested analysis in this article is that it avoids the main problem in all the previous analyses, which is that they try to create a signal analysis for different types of verbal irony and the result is that they fail to cover all these types of verbal irony. As stated above, the main problem in traditional analysis of verbal irony is that it fails to cover all the examples of verbal irony, and this is also the main problem in echoic and pretense accounts of verbal irony. The suggested analysis assumes that ironic sentences have different meanings, making them different types and they should not have a signal analysis for these types. This means that each type of verbal irony should have a suitable analysis. Thus, the suggested analysis treats one type of this phenomenon, specifically, when the ironist communicates the opposite meaning of his/her literal utterance and this analysis is able to account for all the examples of this type of verbal irony.

\section{Conclusion}

This paper discusses the analysis of verbal irony. It summarizes the literature's main accounts of irony, focusing, in particular, on the traditional account, the echoic account and the pretense account; moreover, it discusses problems with each of these accounts. This paper then asserts that verbal ironic expressions have more than one meaning and should thus be subject to more than one analysis. It claims that verbal irony that communicates the opposite of literal meaning should be analyzed as a metaphor containing two subjects with opposite meanings, in which the ironist pretends that they resemble one another. This approach remains in its formative stages and therefore requires critical feedback and further development.

\section{Acknowledgement}

This project was supported by the Deanship of Scientific Research at Prince Sattam Bin Abdulaziz University under the research project 2015/02/4758.

\section{References}

Alzamakhshariy, M. (n.d.). Alkashaf an haqaaq ghwamidh altanziyl. Dar Alkitaab alarabiy.

Camp, E. (2012). Sarcasm, pretense, and the semantics/pragmatics distinction. Nou^s 46(4), 587-634.

Carston, R. and C. Wearing (2015). Hyperbolic language and its relation to metaphor and irony. Journal of Pragmatics 79, 79-92.

Clark, H. H. (1996). Using language. cambridge: Cambridge university press, 1996. pp. xi+ 432. Journal of Linguistics (01).

Clark, H. H. and R. J. Gerrig (1984). On the pretense theory of irony. Currie, G. (2004). Arts and minds. Oxford University Press on Demand. 
Currie, G. and I. Ravenscroft (2002). Recreative minds: Imagination in philosophy and psychol-ogy. Oxford University Press.

Giora, R. (1995). On irony and negation. Discourse processes 19(2), 239-264.

Grice, H. (1975). Logic and conversationin p. cole and j. morgan (eds.) syntax and semantics volume 3: Speech acts.

Grice, H. P. (1978). Further notes on logic and conversation. 1978 1, 13-128.

Jorgensen, J., G. A. Miller, and D. Sperber (1984). Test of the mention theory of irony. Journal of Experimental Psychology: General 113(1), 112.

Kreuz, R. J. and S. Glucksberg (1989). How to be sarcastic: The echoic reminder theory of verbal irony. Journal of Experimental Psychology: General 118(4), 374.

Kumon-Nakamura, S., S. Glucksberg, and M. Brown (1995). How about another piece of pie: The allusional pretense theory of discourse irony. Journal of Experimental Psychology: Gen- eral 124(1), 3.

Lakoff, G. and M. Johnson (2003). Metaphors we live by. 1980. Chicago: U of Chicago P.

Levinson, S. C. (1983). Pragmatics (cambridge textbooks in linguistics).

Nichols, S. and S. Stich (2000). A cognitive theory of pretense. Cognition 74(2), 115-147.

Popa-Wyatt, M. (2014). Pretence and echo: towards an integrated account of verbal irony. Inter- national Review of Pragmatics 6(1), 127-168.

Recanati, F. (2000). Oratio obliqua, oratio recta: an essay on metarepresentation. MIT Press.

Recanati, F. (2004). Literal meaning. Cambridge University Press. Sperber, D. (1984). Verbal irony: Pretense or echoic mention?

Sperber, D. and D. Wilson (1981). Irony and the use-mention distinction. Philosophy 3, 143-184.

Sperber, D. and D. Wilson (1986). Relevance: Communication and Cognition. Cambridge, MA: Harvard University Press.

Sperber, D. and D. Wilson (1998). A reply to seto, hamamoto and yamanashi. Relevance theory: Applications and implications 37, 283.

Utsumi, A. (2000). Verbal irony as implicit display of ironic environment: Distinguishing ironic utterances from nonirony. Journal of Pragmatics 32(12), 1777-1806.

Walton, K. L. (1990). Mimesis as make-believe: On the foundations of the representational arts. Harvard University Press.

Wilson, D. (2006). The pragmatics of verbal irony: Echo or pretence? Lingua 116(10), 1722- 1743.

Wilson, D. and D. Sperber (1992). On verbal irony. Lingua 87(1), 53-76. 